Check for updates

Cite this: RSC Adv., 2018, 8, 13865

\title{
On peroxymonosulfate-based treatment of saline wastewater: when phosphate and chloride co-exist
}

\author{
Bo Sheng, (D) a Ying Huang, ${ }^{a}$ Zhaohui Wang, (D) *ab Fei Yang, ${ }^{a}$ Luoyan $\mathrm{Ai}^{\mathrm{a}}$ \\ and Jianshe Liu*a
}

Both chloride and phosphate are common inorganic anions in industrial wastewater, however, their effects on peroxymonosulfate (PMS)-based oxidation systems are largely unknown. The present results show that addition of chloride ( $>1 \mathrm{mM}$ ) apparently enhanced the degradation of Acid Orange 7 (AO7) independent of the presence of phosphate (PBS) buffer. Both PBS and chloride favored the degradation of AO7, while PBS played a more important role when they co-existed. The degradation efficiency of AO7 was enhanced by increasing the concentration of PBS and chloride. A maximum of absorbable organic halides (AOX) accumulation was observed; indicating some chlorinated byproducts could be initially generated and further oxidized by increasing the reaction time. It is demonstrated that the PBS/PMS system, with a lower AOX formation at the same chloride concentration, is superior to the Co/PMS system, a typical sulfate radical-based system. The active chlorine species $\left(\mathrm{HClO} / \mathrm{Cl}_{2}\right)$ were found to be the dominant oxidants in the presence of higher chloride concentration ( $>50 \mathrm{mM})$ under neutral conditions. The findings of this work may promote the further application of PMS-based oxidation processes in saline effluents treatment.

Received 20th January 2018

Accepted 3rd April 2018

DOI: $10.1039 / \mathrm{c} 8 \mathrm{ra00600h}$

rsc.li/rsc-advances efficiency of atrazine by cobalt/peroxymonosulfate process was better than that of Fenton's reagent. ${ }^{6}$

In the actual water matrix, the common component $\mathrm{Cl}^{-}$could scavenge $\mathrm{SO}_{4}{ }^{--}$and $\mathrm{HO}{ }^{\cdot}$ to form less reactive species (e.g., $\mathrm{Cl}_{2}{ }^{--}$ and $\left.\mathrm{Cl}^{\circ}\right)^{17}$ and thus degradation efficiency of pollutants would be restrained by the presence of chloride. ${ }^{18,19}$ More recently, several investigations have reported the direct reaction between PMS and chloride could lead to the formation of active chlorine species $\left(\mathrm{Cl}_{2} / \mathrm{HClO}\right)$, which are capable of degrading pollutants. ${ }^{20,21} \mathrm{An}$ enhancement of dye decolorization was observed in $\mathrm{PMS} / \mathrm{Cl}^{-}$ system as compared with that in the presence of PMS alone. ${ }^{22}$ Grebel $e$ t $a l .{ }^{23}$ found that the degradation of phenol was markedly enhanced under a high concentration of chloride by $\mathrm{PMS} / \mathrm{Cl}^{-}$ process. However, our previous studies indicate that absorbable organic halides (AOX) was produced and the formation of AOX increased with chloride concentration increasing, ${ }^{24,25}$ owing to the generation of poly-chlorinated byproducts in PMS-based oxidation system. ${ }^{22,26}$ AOX formation and accumulation is a matter of great concern due to their potential toxicity. ${ }^{27}$ Fang et al. ${ }^{24}$ investigated the inhibitory effect of chlorinated byproducts on bioluminescence during the treatment of $0.2 \mathrm{mM} \mathrm{2,4,6-tri-}$ chlophenol (TCP) using a $\mathrm{Co} / \mathrm{PMS} / \mathrm{Cl}^{-}$process. An increase in AOX was observed while the corresponding inhibition varied from $60 \%$ to $86 \%$ after $180 \mathrm{~min}$ reaction time, indicating the adverse impact of AOX. Yuan et al. ${ }^{22}$ demonstrated that AOX value was $2.2 \mathrm{mg} \mathrm{L}^{-1}$ at the application of $0.2 \mathrm{mM}$ chloride while it rose to $3.5 \mathrm{mg} \mathrm{L}^{-1}$ at the application of $100 \mathrm{mM}$ chloride at a reaction time of $120 \mathrm{~min}$ in Co/PMS system.

\footnotetext{
${ }^{a}$ State Environmental Protection Engineering Center for Pollution Treatment and Control in Textile Industry, College of Environmental Science and Engineering; Donghua University, Shanghai, 201620, China. E-mail: zhaohuiwang@dhu.edu.cn; liujianshe@dhu.edu.cn

${ }^{b}$ International Centre for Balanced Land Use (ICBLU), The University of Newcastle, Callaghan, NSW 2308, Australia
} 
In addition to a high concentration of chloride, phosphate is also one of the most common phosphoric components in the industrial wastewater. Large amounts of phosphate are often released from industrial activities, such as leather tanning, chemical fertilizer production and refractory manufacture, ${ }^{28-30}$ leading to phosphate pollution in the wastewater. However, phosphate may affect the efficiency of AOPs during the treatment. ${ }^{31,32}$ Recently, it is reported that PMS could be activated by phosphate to degrade pollutants. ${ }^{33}$ Lou et al. ${ }^{34}$ reported $15.7 \%$ of $0.2 \mathrm{mM} \mathrm{AO7}$ and $37.7 \%$ of $0.25 \mathrm{mM}$ TCP were completely mineralized, respectively while $2.5 \mathrm{mM}$ PMS and $0.1 \mathrm{mM}$ PBS were applied in a PBS/PMS process. Besides, nearly $100 \%$ of $0.05 \mathrm{mM}$ dye was efficiently degraded with the addition of $2.5 \mathrm{mM}$ PMS and 0.1 $\mathrm{M}$ pyrophosphate in a PMS-based process. $^{35}$ In practice, the efficiency of AOPs was always constrained by the presence of various ions. To the best of our knowledge, effect of the single ion on contaminant decomposition based on $\mathrm{SO}_{4}{ }^{--}$has been investigated extensively, while effect of co-existing ions still remains obscure.

In this work, we investigated the effect of both phosphate and chloride in a PMS-based process. The influences of chloride concentration, PBS dosage, and $\mathrm{pH}$ (3.0 to 8.0) on the degradation of Acid Orange 7 (AO7) have been examined. In order to assess the effect of chloride on the formation of chlorinated compounds, AOX determination was carried out. In addition, quenching experiments were conducted to identify active species during the treatment of wastewater. This work may provide a helpful reference for disposal of saline wastewater.

\section{Experimental}

\subsection{Materials}

Oxone ${ }^{\circledR}\left(\left[2 \mathrm{KHSO}_{5} \cdot \mathrm{KHSO}_{4} \cdot \mathrm{K}_{2} \mathrm{SO}_{4}\right]\right.$ salt, 95\%) and Acid Orange 7 (AO7, pure) were supplied by Sigma-Aldrich. For the preparation of phosphate buffer solution, dipotassium hydrogen phosphate $\left(\mathrm{K}_{2} \mathrm{HPO}_{4} \cdot 3 \mathrm{H}_{2} \mathrm{O}\right)$, potassium dihydrogen phosphate $\left(\mathrm{KH}_{2} \mathrm{PO}_{4}\right)$ and phosphoric acid $\left(\mathrm{H}_{3} \mathrm{PO}_{4}\right)$ were mixed proportionally and adjusted to different $\mathrm{pH}$ values. The concentration of $\mathrm{PBS}$ was counted by the content of phosphate anions. $\mathrm{KH}_{2} \mathrm{PO}_{4}, \mathrm{~K}_{2} \mathrm{HPO}_{4} \cdot 3 \mathrm{H}_{2} \mathrm{O}$, $\left(\mathrm{NH}_{4}\right)_{2} \mathrm{SO}_{4}$ and tert-butyl alcohol (TBA) were all purchased from Sinopharm Chemical Reagent Co., Ltd. China and used without further purification. Methanol ( $\mathrm{MeOH}, \mathrm{HPLC}$ grade) was purchased from CNW Technologies GmbH. Barnstead Ultra-Pure water $(>18.2 \mathrm{M} \Omega \mathrm{cm})$ was used throughout the study.

\subsection{Experimental procedures}

All reactions were initiated in $10 \mathrm{~mL}$ beakers by mixing appropriate concentration of phosphate buffer, AO7, chloride, and PMS at ambient temperature. The initial $\mathrm{pH}$ did not change by more than $0.2 \mathrm{pH}$ units during the experiments. The degradation of AO7 was monitored immediately at $484 \mathrm{~nm}$ in time scan mode on an Epscord200 PLUS spectrophotometer. The optimal dosage of PMS was selected according to the preliminary results. AOX determinations were carried out by quantitative analysis (AOX, multi X® 2500, Jena Germany) after enrichment on activated carbon at $950{ }^{\circ} \mathrm{C}$. TOC analyzer (multi N/C@ 3100) was used to measure the TOC. The identification of active species was performed by quenching experiments. These experiments were conducted in duplicate and the average data with their standard deviations were displayed.

\section{Results and discussion}

\subsection{Effect of $\mathrm{Cl}^{-}$concentration}

The degradation of $\mathrm{AO} 7$ followed the pseudo first-order kinetic model under the different concentration of $\mathrm{Cl}^{-}:^{36}$

$$
C=C_{0} \exp (-k t)
$$

where $C_{0}$ is the concentration of $\mathrm{AO} 7$ at the time $t=0$ and $t$, respectively; $k$ is the observed degradation rate constant, which could be estimated from the slopes of the lines in the plots of $-\ln \left(C / C_{0}\right)$ versus reaction time. As shown in Fig. 1, the reaction rate constants were $0.32 \times 10^{-2}, 0.59 \times 10^{-2}, 1.61 \times 10^{-2}$ and $1.75 \times$ $10^{-2} \mathrm{~s}^{-1}$ corresponding to $1,50,200,300 \mathrm{mM}$ chloride, respectively $\left(R^{2}>0.95\right)$. The kinetics data indicate that PBS/PMS oxidation was influenced by chloride. Notably, a dual effect was found on AO7 degradation which is similar to our previous investigations..$^{22,37}$ At a low level of chloride $(<1 \mathrm{mM})$, the degradation rate of $\mathrm{AO} 7$ declined slightly. However, further addition of chloride $(>1 \mathrm{mM})$ apparently accelerated dye degradation. It is supposed that chloride directly reacted with PMS to form active chlorine species for dye degradation at a high chloride concentration. ${ }^{21}$ As the concentration of chloride continually increased from 10 to $300 \mathrm{mM}$, the degradation efficiency of AO7 was enhanced significantly. These results demonstrate the favorable effect of chloride on the PMS-based process. For example, the rate constant of AO7 degradation was about $0.85 \times 10^{-2} \mathrm{~s}^{-1}$ with the presence of $100 \mathrm{mM}$ chloride, higher than that without chloride $(k=0.54 \times$ $\left.10^{-2} \mathrm{~s}^{-1}\right)$.

\subsection{Effect of PBS dosage}

The effect of ionic strength on the degradation rate of rhodamine B was demonstrated by Lou. ${ }^{34}$ As one kind of common inorganic

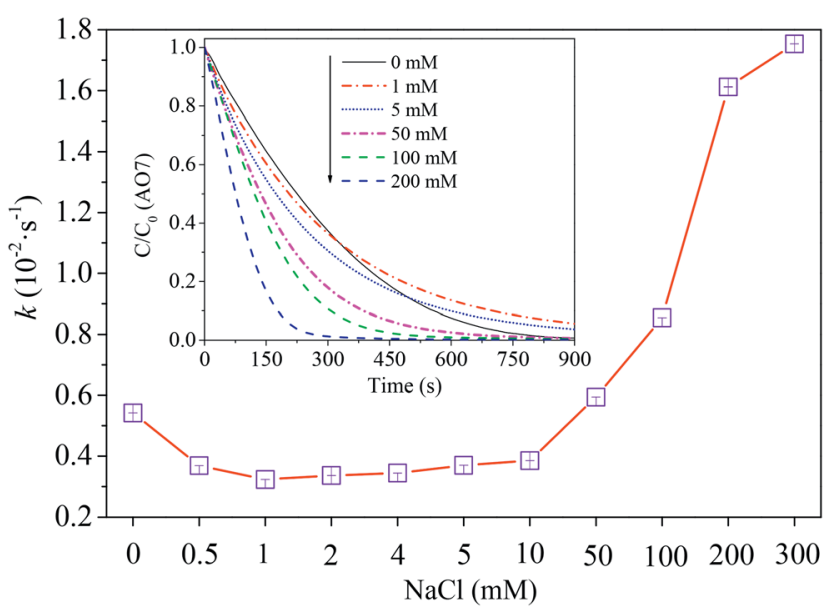

Fig. 1 Effect of chloride concentration on $\mathrm{AO} 7$ degradation rate constants. Conditions: $[\mathrm{AO}]=0.06 \mathrm{mM}$, [PMS] $=2.5 \mathrm{mM}$, [PBS] $=$ $0.12 \mathrm{M}, \mathrm{pH}=7.0$. 
compounds, PBS might have a similar effect on AO7 degradation. Additional tests were carried out at various PBS concentration. As shown in Fig. 2, an enhanced degradation of AO7 was observed with the increase of PBS. This indicates that PMS could be activated by PBS alone (in the absence of chloride) which was in common with the previous study. ${ }^{38}$ As the concentration of PBS varied from 0 to $0.12 \mathrm{M}$, the rate constant of $\mathrm{AO} 7$ degradation increased from 0 to $0.54 \times 10^{-2} \mathrm{~s}^{-1}$. Similar to transition metals, the higher PBS concentration led to the higher degradation efficiency of $\mathrm{AO}^{39} .^{39}$ The degradation of $\mathrm{AO} 7$ in the presence of chloride was also performed. At a low concentration of chloride $(<50 \mathrm{mM})$, the addition of chloride did not affect the degradation profiles, implying the dominant role of PMS activation with PBS. When chloride concentration was up to $300 \mathrm{mM}$, however, the degradation rate constant of AO7 increased to $0.63 \times 10^{-2} \mathrm{~s}^{-1}$ at $[\mathrm{PBS}]_{0}=0 \mathrm{mM}$, which should be caused by the reaction of PMS with chloride. Increasing the concentration of PBS apparently resulted in much more $\mathrm{AO} 7$ degradation. The degradation rate constant of AO7 increased to $1.72 \times 10^{-2} \mathrm{~s}^{-1}$ with the presence of $0.12 \mathrm{M}$ PBS. This result unambiguously confirms that PBS rather than chloride played a key role in the degradation of $\mathrm{AO} 7$ in a PMS-based process and the effect of ionic strength on the reaction rate. The positive impact of PBS dosage on the degradation indicates the suitable application of PMS in treating phosphate abundant wastewater.

\section{3. $\quad$ Effect of pH}

It is reported that the $\mathrm{pH}$ would strongly influence the degradation efficiency of pollutants in a PMS-based process. ${ }^{40}$ Therefore, effect of $\mathrm{pH}$ on $\mathrm{AO} 7$ degradation were further examined by virtue of the buffer effect of phosphate-based solution. Fig. 3 depicts the degradation rate of AO7 was evidently enhanced with the increase of $\mathrm{pH}$ in the absence of chloride. PMS is stable at $\mathrm{pH}<4.0$, while it becomes unstable at $\mathrm{pH}>7.0 .^{41}$ Thus, faster degradation rates of dye were expected under neutral or alkaline conditions. It should be noted that the addition of chloride could enhance AO7 degradation in the

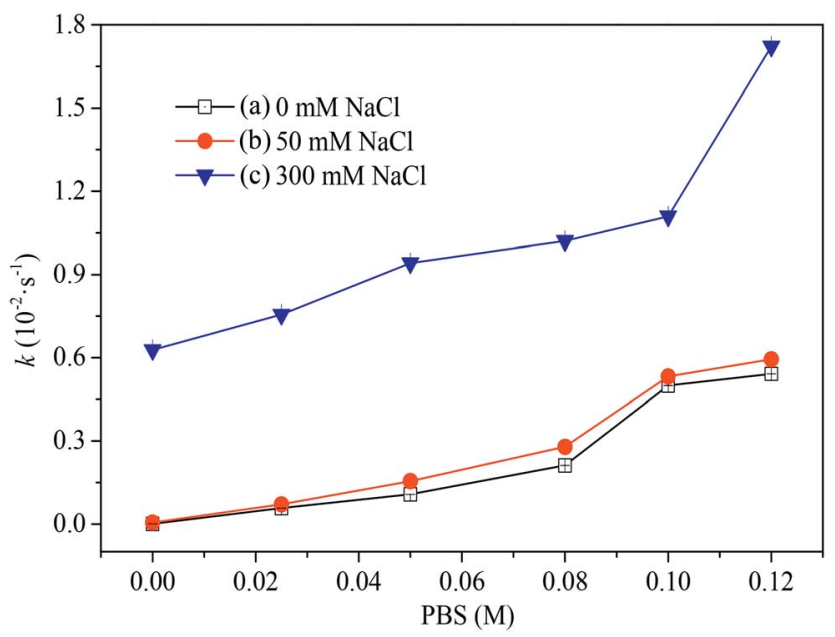

Fig. 2 Effect of PBS concentration on $\mathrm{AO} 7$ degradation rate constants. Conditions: $[\mathrm{AO} 7]=0.06 \mathrm{mM},[\mathrm{PMS}]=2.5 \mathrm{mM}, \mathrm{pH}=7.0$. (a) $[\mathrm{NaCl}]=$ $0 \mathrm{mM}$. (b) $[\mathrm{NaCl}]=50 \mathrm{mM}$. (c) $[\mathrm{NaCl}]=300 \mathrm{mM}$. examined $\mathrm{pH}$ of 3.0-8.0. Under the acidic conditions $(\mathrm{pH}<4.0)$, chloride is directly oxidized via a two-electron process (eqn (2) and (3)), while the contribution of the reaction between PBS and PMS should be negligible. A further increase of $\mathrm{pH}$ to 6.0 resulted in a significant decrease in degradation rate. The decomposition of $\mathrm{HClO}$ (1.49 V versus $\mathrm{NHE})$ to $\mathrm{ClO}^{-}$with lower oxidation potential ( $0.94 \mathrm{~V}$ versus $\mathrm{NHE}$ ) led to lower dye degradation efficiency. ${ }^{42}$ As the $\mathrm{pH}$ increased from 7.0 to 8.0, degradation efficiency of AO7 was enhanced significantly. For example, AO7 degradation rate increased from $0.761 \times 10^{-2}$ to $1.621 \times 10^{-2} \mathrm{~s}^{-1}$ when chloride concentration varied from 100 to $200 \mathrm{mM}$ chloride at $\mathrm{pH}$ 7.0. The oxidation capacity of the direct reaction between PMS and chloride declined, whereas the reaction between PBS and PMS rose remarkably in the examined $\mathrm{pH}$ of 7.0-8.0. When $\mathrm{pH}$ was 7.0-8.0, the reaction between PMS and PBS governed the overall degradation reaction and a favorable effect on dye degradation were found. Hence, under the various PBS/PMS reaction condition, a higher AO7 degradation efficiency was observed in neutral solution. The result was in good with the previous report by Lou. ${ }^{35}$

$$
\begin{gathered}
2 \mathrm{Cl}^{-}+\mathrm{HSO}_{5}{ }^{-}+\mathrm{H}^{+} \rightarrow \mathrm{SO}_{4}{ }^{2-}+\mathrm{Cl}_{2}+\mathrm{H}_{2} \mathrm{O} \\
\mathrm{Cl}^{-}+\mathrm{HSO}_{5}{ }^{-} \rightarrow \mathrm{SO}_{4}{ }^{2-}+\mathrm{HClO}
\end{gathered}
$$

\subsection{AOX formation}

The coexistence of both chloride and phosphate apparently favored PMS-based process for efficient dye degradation. However, AOX accumulation occurs if chloride is oxidized to reactive chlorine species or radicals (such as $\mathrm{Cl}^{\cdot}$ and $\mathrm{Cl}_{2}{ }^{-}$) which further chlorinate organic compounds. ${ }^{22}$ Thus, it is necessary to quantify AOX level during the reaction in the presence of chloride. Fig. 4 compares AOX values under different chloride concentration ( $5 \mathrm{mM}, 50 \mathrm{mM}$ ). Measurable AOX was not observed at $t=0 \mathrm{~min}$. At a low concentration of chloride ( $5 \mathrm{mM})$, an enhanced AOX formation was observed and

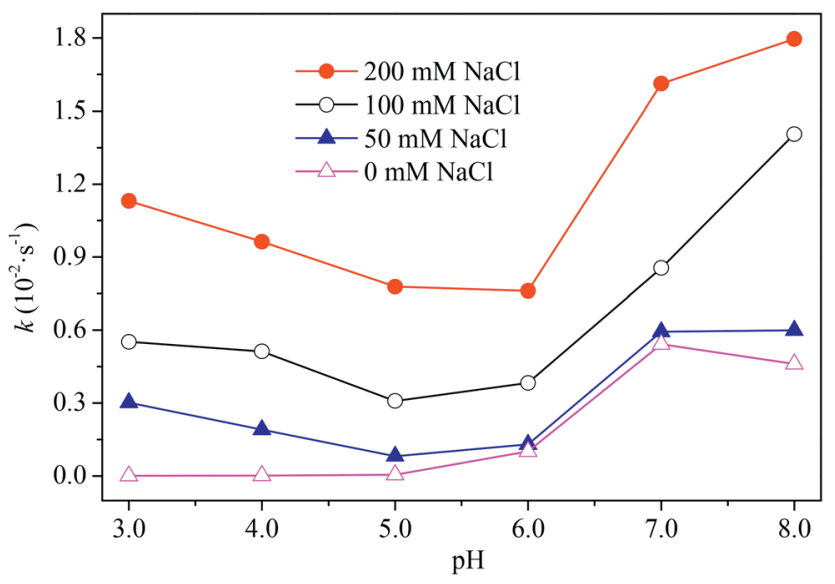

Fig. 3 Effect of $\mathrm{pH}$ on $\mathrm{AO} 7$ degradation rate constants in the presence of chloride. Conditions: $[\mathrm{AO}]=0.06 \mathrm{mM}$, [PMS $]=2.5 \mathrm{mM}$, [PBS] $=$ $0.12 \mathrm{M}$. 
AOX declined after $15 \mathrm{~h}$. At a higher level of chloride (50 mM), a significant AOX accumulation happened, while a decay of AOX was observed after $3 \mathrm{~h}$. Increasing chloride concentration resulted in higher AOX values, in corresponding with the previous studies. ${ }^{22,24}$ The decrease of AOX implies that some chlorinated byproducts could be mineralized after a long reaction time. In addition, it should be much difficult to eliminate overall AOX at a higher chloride concentration due to the simultaneous occurrence of dechlorination and rechlorination. $^{25}$

Co/PMS system, a common system to produce sulfate radicals, was compared with the PBS/PMS system on AOX formation. Fig. 5 shows the overall AOX formation and reduction in the $\mathrm{Co} / \mathrm{PMS} / \mathrm{Cl}^{-}$system. When chloride concentration varied from $5 \mathrm{mM}$ to $50 \mathrm{mM}$, the enhanced AOX values was also observed. The maximum AOX values in a PBS/PMS system were $4.04 \mathrm{mg} \mathrm{L}^{-1}$ and $4.37 \mathrm{mg} \mathrm{L}^{-1}$, respectively, while the corresponding values increased dramatically from $9.17 \mathrm{mg} \mathrm{L}^{-1}$ and $10.19 \mathrm{mg} \mathrm{L}^{-1}$ in the Co/PMS system, respectively. A similar phenomenon was reported during the treatment of 2,4,6-trichlophenol in a $\mathrm{Co} / \mathrm{PMS} / \mathrm{Cl}^{-}$system. ${ }^{18}$ This comparison in AOX formation demonstrates that chloride in the PBS/PMS system cannot be effectively activated than in the Co/PMS process. It is suggested that PBS/PMS process is promising for industrial wastewater treatment due to the less formation of AOX.

\subsection{TOC removal}

The mineralization of AO7 in the Co/PMS system and PBS/PMS system was examined by varying the initial content of chloride ion, respectively. Fig. 6 and 7 show that removal rates of TOC increased over the reaction time in these two systems. Increasing the concentration of chloride was favorable to TOC removal in a PBS/PMS process, but apparently decreased the extent of $\mathrm{AO} 7$ mineralization in a Co/PMS process, in good agreement with our previous observation. ${ }^{22}$ The contrasting TOC results demonstrate the difference in reaction mechanism between Co/PMS and PBS/PMS processes.

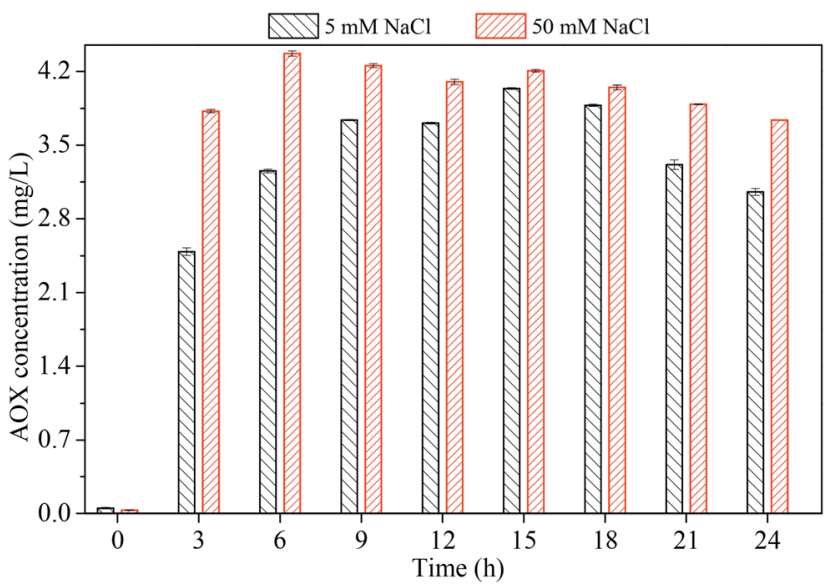

Fig. 4 AOX formation in the PBS/PMS system as a function of time. Conditions: $[\mathrm{AO}]=0.2 \mathrm{mM}$, $[\mathrm{PBS}]=0.12 \mathrm{M}$, [PMS $]=8 \mathrm{mM}$.

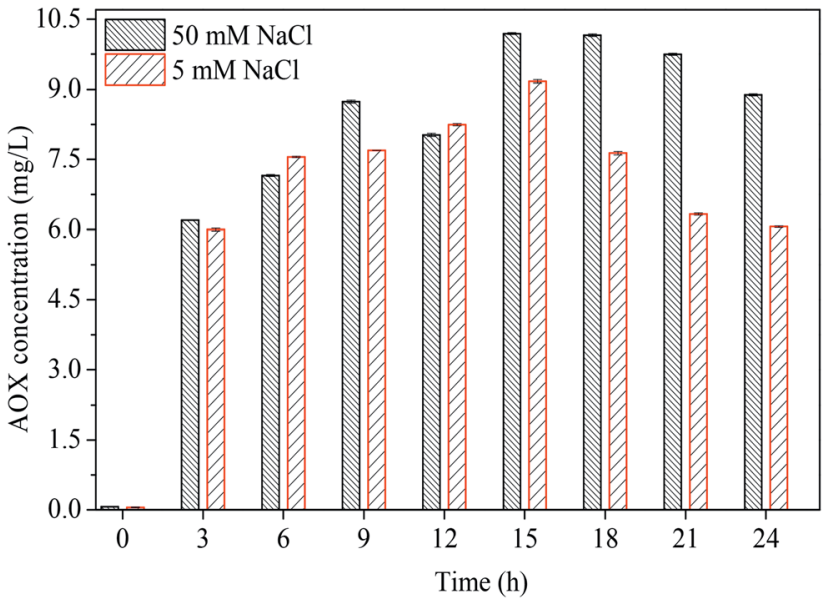

Fig. $5 \mathrm{AOX}$ values of $\mathrm{AO} 7$ degradation in the Co/PMS system as a function of reaction time. Conditions: $[A O 7]=0.2 \mathrm{mM},\left[\mathrm{Co}^{2+}\right]=$ $0.1 \mathrm{mM},[\mathrm{PMS}]=10 \mathrm{mM}$.

\subsection{Identification of the reactive species}

Generally, $\mathrm{HO}^{\circ}$ can be generated in the $\mathrm{SO}_{4}{ }^{-}{ }^{-}$-based process due to the reaction of $\mathrm{SO}_{4}{ }^{--}$with hydroxide $\left(7.3 \times 10^{7} \mathrm{M}^{-1} \mathrm{~s}^{-1}\right)$ and water $\left(10^{3}\right.$ to $\left.10^{4} \mathrm{~s}^{-1}\right)$ under neutral conditions. ${ }^{43,44}$ The organic pollutant can be decomposed by both $\mathrm{SO}_{4}{ }^{-}$and $\mathrm{HO}^{\circ}$. Both methanol and tert-butyl alcohol were selected as scavengers due to the reactivity of methanol toward $\mathrm{SO}_{4}{ }^{-}-\left(7.8 \times 10^{6} \mathrm{M}^{-1} \mathrm{~s}^{-1}\right)^{45}$ and $\mathrm{HO}^{\cdot}\left(9.7 \times 10^{8} \mathrm{M}^{-1} \mathrm{~s}^{-1}\right)^{46}$ and the reactivity of tert-butyl alcohol toward $\mathrm{HO}^{\cdot}\left((3.6\right.$ to 7.8$\left.) \times 10^{8} \mathrm{M}^{-1} \mathrm{~s}^{-1}\right) .{ }^{47}$ As shown in Fig. 8 , in the absence of chloride, the degradation of AO7 was successfully inhibited after adding methanol and a similar inhibition was observed with the addition of TBA. The coexistence of both $\mathrm{SO}_{4}{ }^{-}$and $\mathrm{HO}^{\cdot}$ may be responsible for $\mathrm{AO} 7$ degradation. However, chloride may mitigate the inhibitory

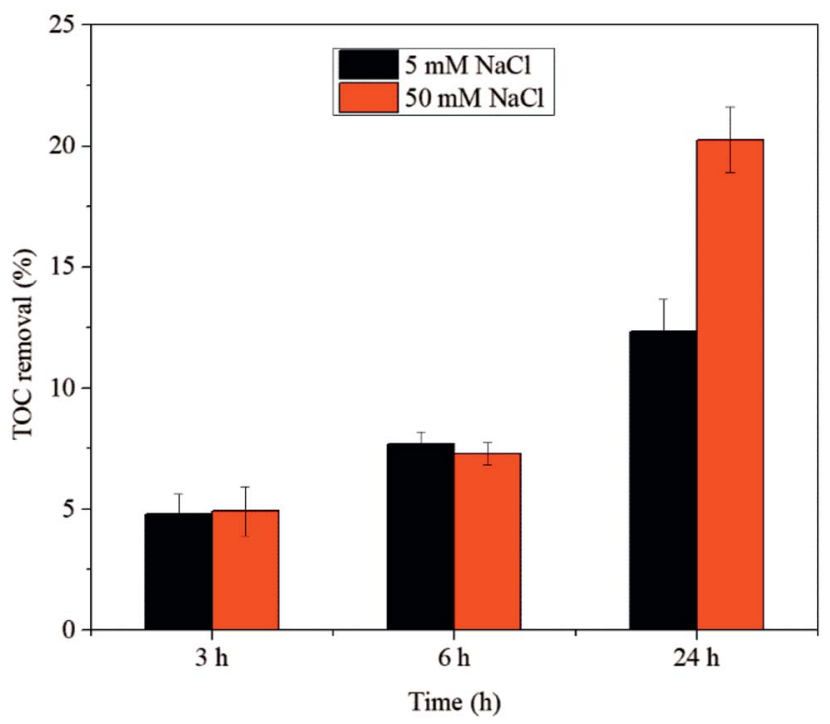

Fig. 6 TOC removal of $\mathrm{AO}$ in the PBS/PMS system as a function of reaction time. Conditions: $[\mathrm{AO}]=0.2 \mathrm{mM}$, $[\mathrm{PBS}]=0.12 \mathrm{M}$, $[\mathrm{PMS}]=$ $8 \mathrm{mM}$. 


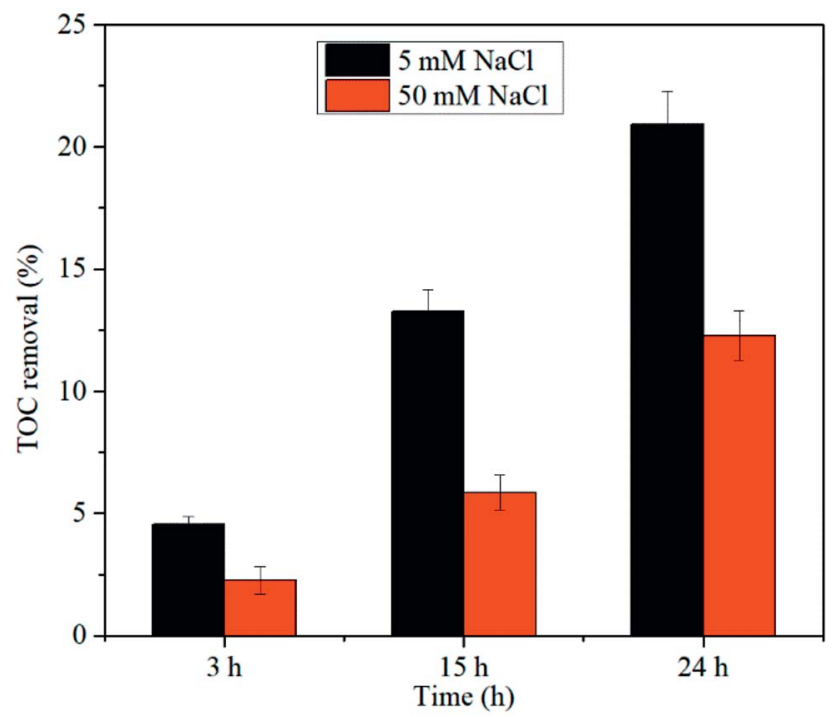

Fig. 7 TOC removal of $A O 7$ in the Co/PMS system as a function of reaction time. Conditions: $[\mathrm{AO}]=0.2 \mathrm{mM},\left[\mathrm{Co}^{2+}\right]=0.1 \mathrm{mM}$, $[\mathrm{PMS}]=$ $10 \mathrm{mM}$.

effect of two kinds of scavengers. At low concentration of chloride ( $<50 \mathrm{mM}$ ), degradation rates of AO7 increased slightly. As chloride concentration increased from 50 to $300 \mathrm{mM}$, however, the enhanced degradation of $\mathrm{AO} 7$ was observed. The failure of scavengers to inhibit $\mathrm{AO} 7$ degradation suggests that other active species, instead of both $\mathrm{SO}_{4}{ }^{--}$and $\mathrm{HO}^{\circ}$, contributed to the degradation of AO7. The high level of chloride $(>50 \mathrm{mM})$ resulted in a high concentration of $\mathrm{HClO} / \mathrm{Cl}_{2}$ which are responsible for pollutant degradation. Thus, $\mathrm{HClO} / \mathrm{Cl}_{2}$ might play a key role in $\mathrm{AO} 7$ oxidation at the higher chloride concentration (>50 $\mathrm{mM})$.

\subsection{Mechanism discussion}

In the PBS/PMS system, phosphate can effectively activate peroxymonosulfate (PMS) to produce oxidizing radicals for dye

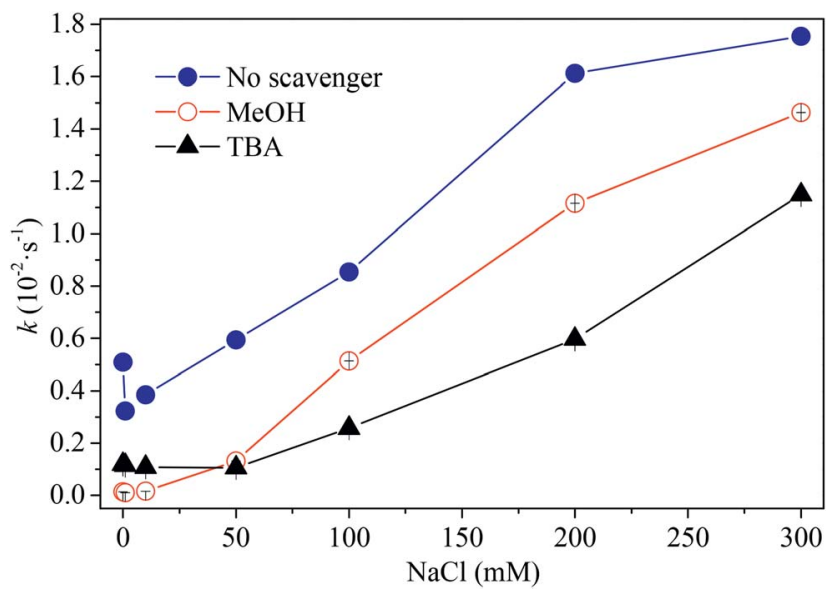

Fig. 8 Effect of radical scavengers on dye degradation rate constants Conditions: $[\mathrm{PMS}]=2.5 \mathrm{mM},[\mathrm{PBS}]=0.12 \mathrm{M}$, $[\mathrm{AO}]=0.06 \mathrm{mM}$, $[\mathrm{MeOH}]=1.5 \mathrm{M},[\mathrm{TBA}]=1.5 \mathrm{M}$. degradation. Measurable degradation was not observed in the absence of PBS and the increase of PBS concentration led to the enhanced degradation rates of $\mathrm{AO} 7$, indicating the crucial role of PBS for PMS activation. The PBS/PMS system can be subject to $\mathrm{pH}$ changes, with the best performance at $\mathrm{pH}$ 7.0. In the PMS/ $\mathrm{Cl}^{-}$system, the generation of HClO via two-electron reaction between PMS and $\mathrm{Cl}^{-}$could lead to $\mathrm{AO} 7$ degradation. However, the decomposition of $\mathrm{HClO}$ to $\mathrm{ClO}^{-}$led to a lower dye degradation efficiency in weakly acidic solution. Higher chloride concentration could favor higher dye degradation efficiency. Therefore, faster degradation of AO7 was expected in strongly acidic and higher chloride solution. In the $\mathrm{PBS} / \mathrm{PMS} / \mathrm{Cl}^{-}$system, a rapid $\mathrm{AO} 7$ degradation was observed. Both high chloride concentration and higher $\mathrm{pH}$ could accelerate dye degradation. Both $\mathrm{SO}_{4}{ }^{-}$and $\mathrm{HO}^{\circ}$ were not detected with high levels of chloride at $\mathrm{pH}$ 7.0. Chlorine in the form of a liquid or gas has been applied to decolorization of dyes. ${ }^{48}$ PMS activation by both PBS and chloride may result in rapid dye degradation.

\section{Conclusions}

Degradation efficiency of the PMS/Cl ${ }^{-}$, PBS/PMS, and PBS/PMS/ $\mathrm{Cl}^{-}$systems was investigated by varying the contents of chloride and PBS. An efficient AO7 degradation was observed while $0.12 \mathrm{M}$ PBS and chloride (>50 $\mathrm{mM}$ ) were applied in a PBS/PMS system at $\mathrm{pH}$ 7.0. The results shed light on the key role of PBS in dye degradation. Higher concentration of chloride ion could lead to more AOX accumulation. The low level of AOX accumulation with the same chloride concentration indicates less chlorination of organic compounds occurs in the PBS/PMS system as compared to the typical Co/PMS system. In contrast to the role of chloride in the Co/PMS system, increasing chloride ion could enhance the mineralization of AO7 in the PBS/ PMS system, though with a low removal efficiency. Besides, the failure of both methanol and TBA to inhibit degradation of organics indicates low reactivity between reactive species and scavengers. $\mathrm{HClO} / \mathrm{Cl}_{2}$ might be the dominant active oxidants with a high concentration of chloride under neutral conditions. The degradation of AO7 could undergo a non-radical reaction pathway under a chloride-rich condition. The high reactivity and wide effective $\mathrm{pH}$ range made $\mathrm{PBS} / \mathrm{PMS}$ oxidation a promising AOP for metal-free removal of pollutants.

\section{Conflicts of interest}

There are no conflicts to declare.

\section{Acknowledgements}

This work was supported by National Key Research and Development Program of China (2016YFC0400501/2016YFC0400509) and the National Natural Science Foundation of China (NSFC) (No. 21677031). Z. H. W. would like to thank the partial support of Australian Research Council (DE150101477). 


\section{Notes and references}

1 S. Y. Yang, X. Yang, X. T. Shao, R. Niu and L. L. Wang, J. Hazard. Mater., 2011, 186, 659.

2 P. K. Malik and S. K. Saha, Sep. Purif. Technol., 2003, 31, 241. 3 A. Azam and A. Hamid, J. Hazard. Mater., 2006, 133, 167.

4 A. Hussein and M. Scholz, Environ. Sci. Pollut. Res., 2018, 25, 6870.

5 X. Y. Chen, X. L. Qiao, D. G. Wang, J. Lin and J. W. Chen, Chemosphere, 2007, 67, 802.

6 G. P. Anipsitakis and D. D. Dionysiou, Environ. Sci. Technol., 2003, 37, 4790.

7 G. P. Anipsitakis and D. D. Dionysiou, Appl. Catal., B, 2004, 54, 155.

8 S. H. Do, J. H. Jo, Y. H. Jo, H. K. Lee and S. H. Kong, Chemosphere, 2009, 77, 1127.

9 X. W. Liu, T. Q. Zhang, Y. C. Zhou, L. Fang and Y. Shao, Chemosphere, 2013, 93, 2717.

10 S. L. Wang, N. Zhou, S. Wu, Q. Zhang and Z. Yang, Ultrason. Sonochem., 2015, 23, 128.

11 Z. S. Wei, F. A. Villamena and L. K. Weavers, Environ. Sci. Technol., 2017, 51, 3410.

12 P. H. Shi, X. L. Wang, X. J. Zhou, Y. L. Min, J. C. Fan and W. F. Yao, $R S C A d v ., 2015,5,34125$.

13 S. Muhammad, E. Saputra, H. Q. Sun, J. C. Izidoro, D. A. Fungaro, H. M. Ang, M. O. Tade and S. B. Wang, $R S C$ Adv., 2012, 2, 5645.

14 C. D. Qi, X. T. Liu, J. Ma, C. Y. Lin, X. W. Li and H. J. Zhang, Chemosphere, 2016, 151, 280.

15 X. G. Duan, H. Q. Sun, J. Kang, Y. X. Wang, S. Indrawirawan and S. B. Wang, ACS Catal., 2015, 5, 4629.

16 L. Tang, Y. N. Liu, J. J. Wang, G. M. Zeng, Y. C. Deng, H. R. Dong, H. P. Feng, J. J. Wang and B. Peng, Appl. Catal., B, 2018, 231, 1.

17 A. E. Grigorev, I. E. Makarov and A. K. Pikaev, High Energy Chem., 1987, 21, 99.

18 L. Xu, R. X. Yuan, Y. G. Guo, D. X. Xiao, Y. Cao, Z. H. Wang and J. S. Liu, Chem. Eng. J., 2013, 217, 169.

19 J. Zhou, J. H. Xiao, D. X. Xiao, Y. G. Guo, C. L. Fang, X. Y. Lou, Z. H. Wang and J. S. Liu, Chemosphere, 2015, 134, 446.

20 N. Narender, P. Srinivasu, S. J. Kulkarni and K. V. Raghavan, Synth. Commun., 2002, 32, 279.

21 P. Wang, S. Y. Yang, L. Shan, R. Niu and X. T. Sha, J. Environ. Sci., 2011, 23, 1799.

22 R. X. Yuan, S. N. Ramjaun, Z. H. Wang and J. S. Liu, J. Hazard. Mater., 2011, 196, 173.

23 J. E. Grebel, J. J. Pignatello and W. A. Mitch, Environ. Sci. Technol., 2010, 44, 6822.
24 C. L. Fang, D. X. Xiao, W. Q. Liu, X. Y. Lou, J. Zhou, Z. H. Wang and J. S. Liu, Chemosphere, 2016, 144, 2415.

25 Z. H. Wang, M. Feng, C. L. Fang, Y. Huang, L. Y. Ai, F. Yang, Y. Xue, W. Q. Liu and J. S. Liu, RSC Adv., 2017, 7, 12318.

26 J. Kiwi, A. Lopez and V. Nadtochenko, Environ. Sci. Technol., 2000, 34, 2162.

27 J. C. Alexander and C. R. Ramirez-Cortina, Ozone: Sci. Eng., 2016, 38, 181.

28 R. A. Palop and A. Marsal, J. Am. Leather Chem. Assoc., 2004, 99, 405.

29 G. A. Kazemi, Hydrogeol. J., 2004, 12, 723.

30 J. Nunthanid, A. Laungtana-Anan, P. Sriamornsak, S. Limmatvapirat, S. Puttipipatkhachorn, L. Y. Lim and E. Khor, J. Controlled Release, 2004, 99, 15.

31 M. Muthukumar and N. Selvakumar, Dyes Pigm., 2004, 62, 221.

32 C. Hu, J. C. Yu, Z. Hao and P. K. Wong, Appl. Catal., B, 2003, 46, 35.

33 S. Y. Yang, P. Wang, X. Yang, L. Shan, W. Y. Zhang, X. T. Shao and R. Niu, J. Hazard. Mater., 2010, 179, 552.

34 X. Y. Lou, Y. G. Guo, D. X. Xiao, Z. H. Wang, S. Y. Lu and J. S. Liu, Environ. Sci. Pollut. Res., 2013, 20, 6317.

35 X. Y. Lou, C. L. Fang, Z. N. Geng, Y. M. Jin, D. X. Xiao, Z. H. Wang, J. S. Liu and Y. G. Guo, Chemosphere, 2017, 173, 529.

36 Y. E. Yan and F. W. Schwartz, Environ. Sci. Technol., 2000, 34, 2535.

37 Y. Huang, F. Yang, L. Y. Ai, M. Feng, C. Wang, Z. H. Wang and J. S. Liu, Chemosphere, 2017, 179, 331.

38 M. Sanchez, A. Hadasch, R. T. Fell and B. Meunier, J. Catal., 2001, 202, 177.

39 P. Nfodzo and H. Choi, Chem. Eng. J., 2011, 174, 629.

40 O. S. Furman, A. L. Teel and R. J. Watts, Environ. Sci. Technol., 2010, 44, 6423.

41 Y. H. Guan, J. Ma, X. C. Li, J. Y. Fang and L. W. Chen, Environ. Sci. Technol., 2011, 45, 9308.

42 C. M. Gerritsen and D. W. Margerum, Inorg. Chem., 1990, 29, 2757.

43 Y. Feng, P. H. Lee, D. L. Wu and K. M. Shih, Environ. Sci. Technol., 2017, 51, 2312.

44 L. R. Bennedsen, J. Muff and E. G. Sogaard, Chemosphere, 2012, 86, 1092.

45 H. Eibenberger, S. Steenken, P. O'Neill and D. SchulteFrohlinde, J. Phys. Chem., 1978, 82, 749.

46 G. V. Buxton, C. L. Greenstock, W. P. Helman and A. B. Ross, J. Phys. Chem. Ref. Data, 1988, 17, 513.

47 C. L. Clifton and R. E. Huie, Int. J. Chem. Kinet., 1989, 21, 677. 48 K. Hamada, M. Nishizawa, D. Yoshida and M. Mitsuishi, Dyes Pigm., 1998, 36, 313. 